\title{
The Budd-Chiari syndrome in pregnancy
}

\author{
M. Tiliacos \\ M.B., M.D. \\ A. Tsoulias \\ M.B., M.D.
}

\author{
E. EUDAIMON \\ M.B., M.D.
}

D. TSANTOULAS

M.B., M.D.

E. KOKKA

M.B., M.D.

\section{S. Aphentoglou M.B.}

\author{
C. Metzantonakis \\ M.B., M.D.
}

Third Department of General Medicine, Evangelismos Hospital, Athens, Greece

\begin{abstract}
Summary
A case of Budd-Chiari syndrome in a young woman, which started probably in the last trimester of pregnancy, is described. The diagnosis was made clinically and was confirmed by inferior venacavography and on exploratory laparotomy. The possible connection of the syndrome with the pregnancy is discussed.
\end{abstract}

\section{Introduction}

The Budd-Chiari syndrome, due to occlusion of the hepatic veins by tumour or thrombus arising either locally or by extension from the inferior vena cava is a rare condition. In his thorough review of the syndrome Parker (1959) described 149 cases. In the majority of the reported cases the diagnosis was made at post-mortem (Parker, 1959, Westcott, 1973) and, in a few of them, only during the last 20 years, was the diagnosis made in life, owing to the development of new techniques such as liver biopsy, hepatic venography, selective hepatic arteriography, inferior venacavography and liver scintiscan.

The patient in the present case was a young, pregnant woman, and the diagnosis was made ante mortem. On this occasion, the possible connection of the syndrome with pregnancy is discussed.

\section{Case report}

A 25-year-old housewife was admitted to the medical department of Evangelismos hospital in February 1976, because of gross abdominal distension. The patient had had a normal delivery 12 days before admission. During the last trimester of preg-

Correspondence: Dr M. Tiliacos, M.B., M.D., 28 Akathimias St, Athens, Greece. nancy the abdomen had been so unusually large that $\rightarrow$ the family obstetrician had suspected twin gestation. At the same time she complained of a moderately? severe right hypochondrial pain. The enlargment of the abdomen persisted after the delivery. The presence of ascites was confirmed and the patie $\vec{t} \overrightarrow{0}$ was admitted to hospital. On examination the patient o was slightly pale and moderately jaundiced. To abdomen was grossly distended owing to the pre-? sence of ascites. The inferior epigastric veins were distended because of established collateral circulation. The liver was enlarged, hard, nodular and $\frac{\circ}{\Phi}$ slightly tender. There was no hepato-jugular reflux. $\stackrel{\varrho}{\rightleftharpoons}$ The spleen was palpable, but with great difficulty $\overrightarrow{\vec{O}}$ because of ascites.

\section{Laboratory investigations}

Haematocrit, $35 \%$; WBC, $9.8 \times 10^{9} / 1$ (polymorphs 흑 $80 \%$ ); platelets, $250.0 \times 10^{\circ} / 1$; ESR, $76 \mathrm{~mm}$; serum bilirubin, $21.4 \mu \mathrm{mol} / 1$ (conj., $10 \mu \mathrm{mol} / \mathrm{l}$ ); SGOT, 65 i.u./1; SGPT, 65 i.u./1; alkaline phosphatase, $22 \mathrm{KAu}$, fasting blood sugar $4.7 \mathrm{mmol} / \mathrm{l}$; blood urea, 웅 $6.3 \mathrm{mmol} / \mathrm{l}$; serum sodium, $147 \mathrm{mmol} / \mathrm{l}$; potassium $5.4 \mathrm{mmol} / \mathrm{l}$; serum proteins, $70 \mathrm{~g} / 1$ (albumin $36 \mathrm{~g} / \mathrm{l}$, 옥 globulin $34 \mathrm{~g} / \mathrm{l})$; immunoglobulins: IgG $12.5 \mathrm{~g} / \mathrm{l}$; 응 IgA $2.86 \mathrm{~g} / 1$; IgM $2.00 \mathrm{~g} / \mathrm{l}$. Prothrombin time 11.3/ $13.5 \mathrm{sec}$; $\alpha$-feto-protein, negative; $\mathrm{HB}_{5} \mathrm{Ag}$, negative. N Bromsulphthalein retention, $18 \%$ after $45 \mathrm{~min}$.

\section{Examination of the ascitic fluid}

Protein $300 \mathrm{~g} / \mathrm{l}$, many white cells (polymorphs $65 \%$ ), culture negative, examination for acid-fast $\stackrel{\varrho}{\subset}$ bacilli negative, examination for malignant cells $\stackrel{\varnothing}{\Phi}$ negative (three times). Chest X-ray showed eleva- ? tion of the right diaphragm. ECG showed sinus tachycardia. The liver scan (Fig. 1) showed great 


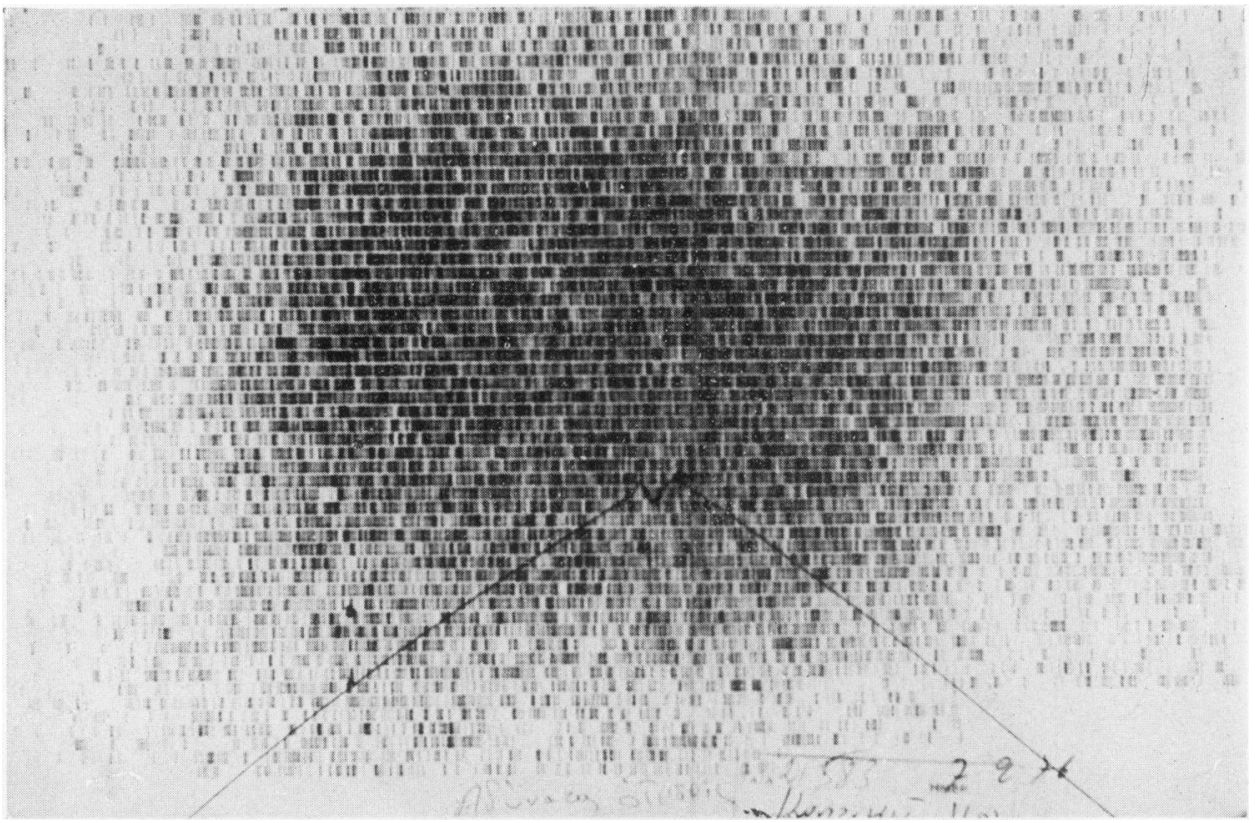

Fig. 1. Liver scan anterior view: the hypertrophied caudate lobe is seen as an area of increased uptake superimposed on the central proportion of the liver.

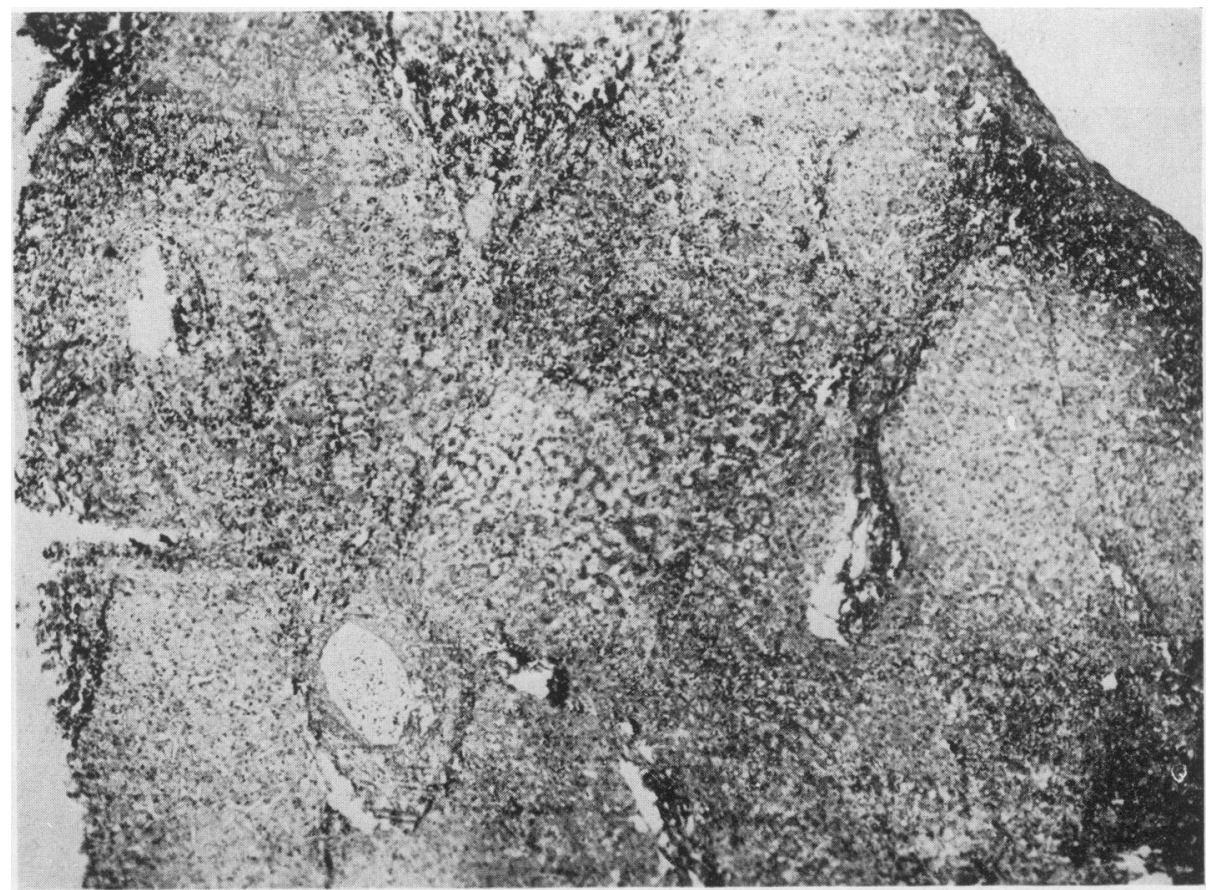

FIG. 2. Liver biopsy: congested and haemorrhagic liver parenchyma with thrombotic hepatic veins. $\mathrm{HE}, \times 10$. 


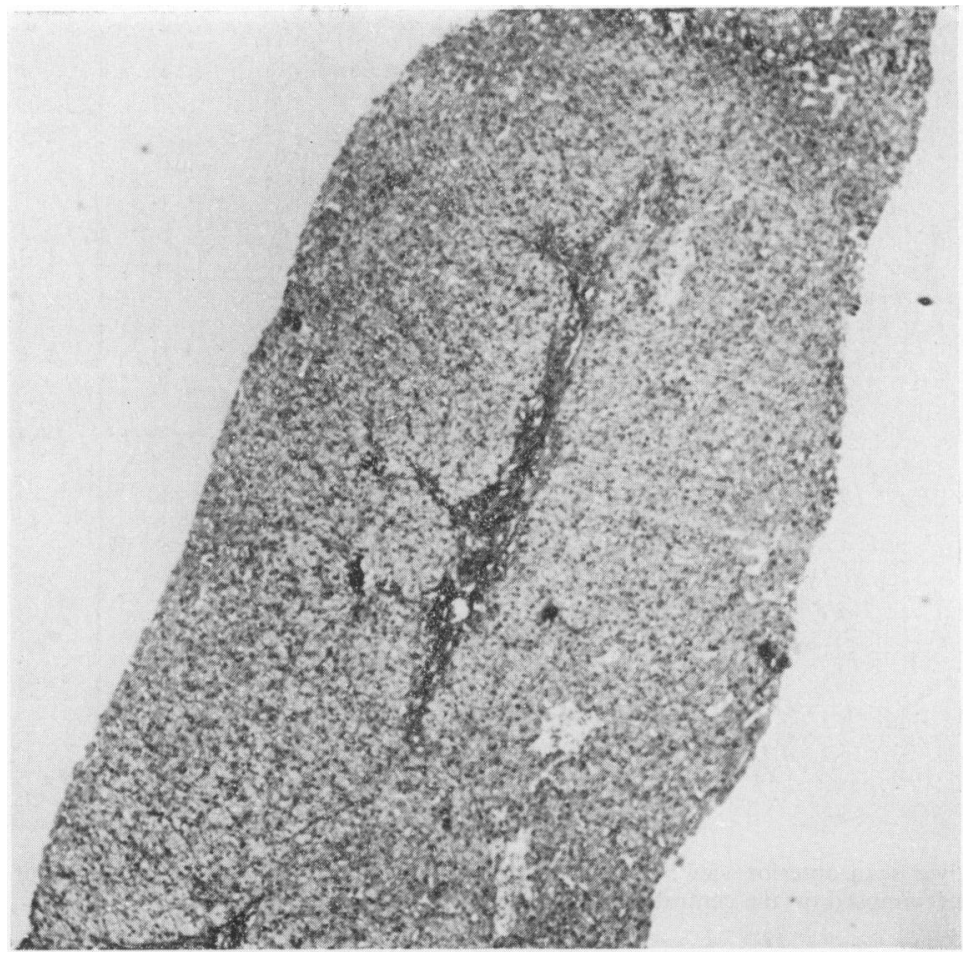

Fig. 3. Needle liver biopsy. Moderate portal fibrosis, some dilated central veins. $\mathrm{HE}, \times 40$.

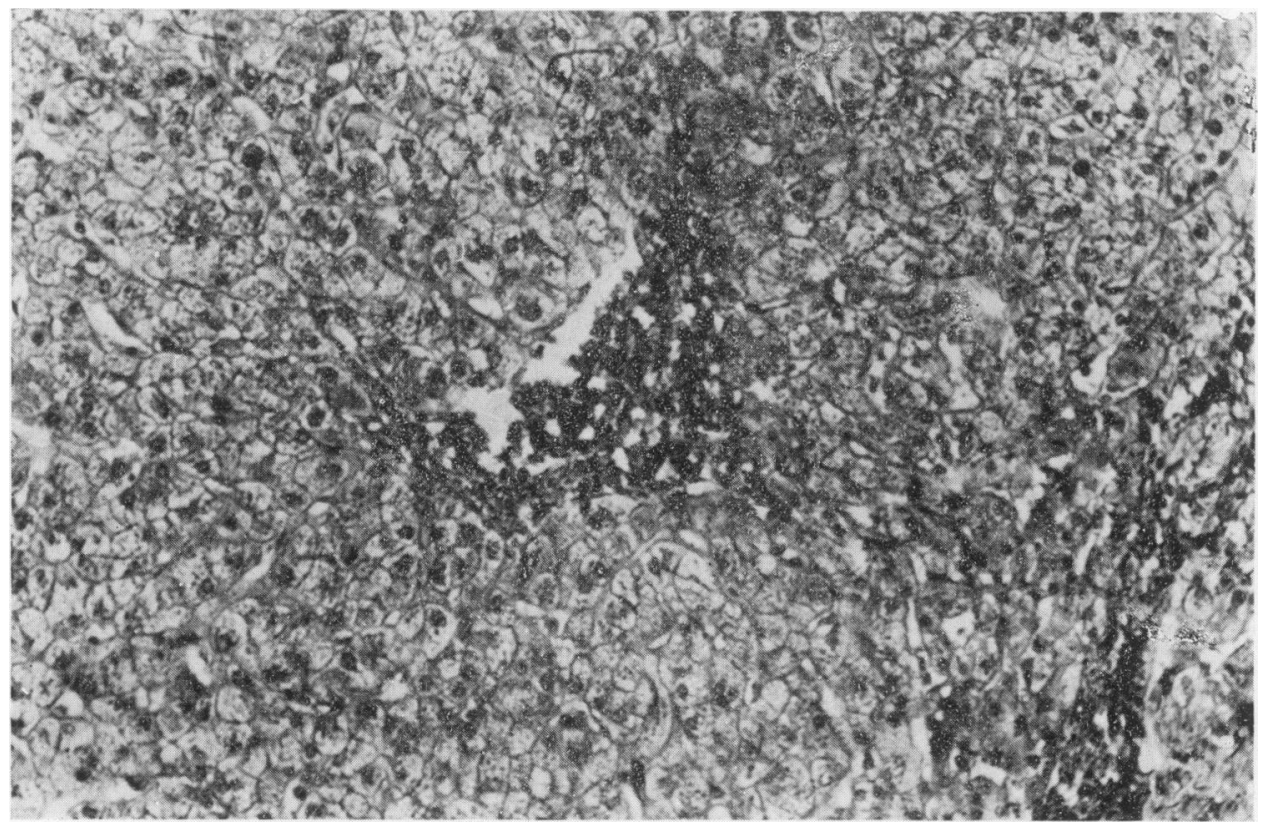

FIg. 4. Hepatic vein filled with thrombus. HE, $\times 40$. 


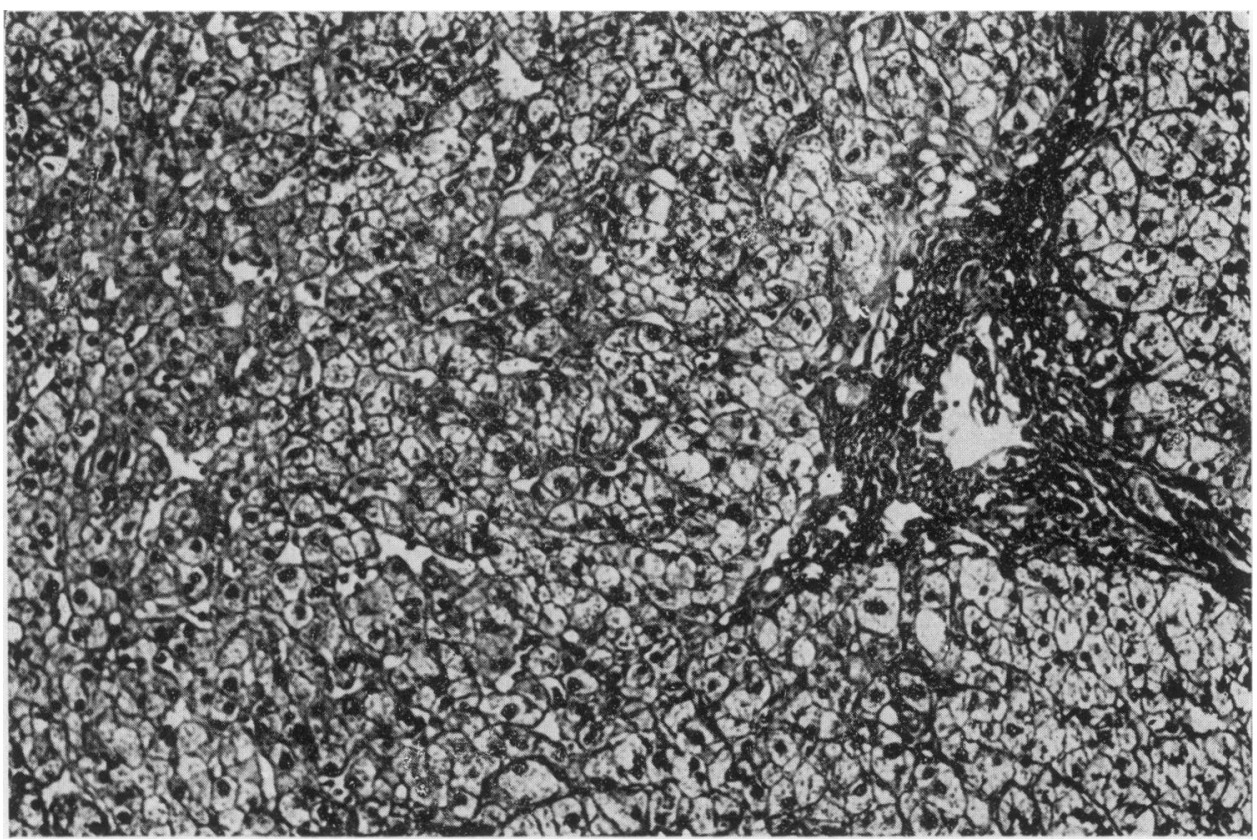

FIG. 5. Needle liver biopsy. Moderate portal fibrosis, liver plates nearly normal. HE, $\times 40$.

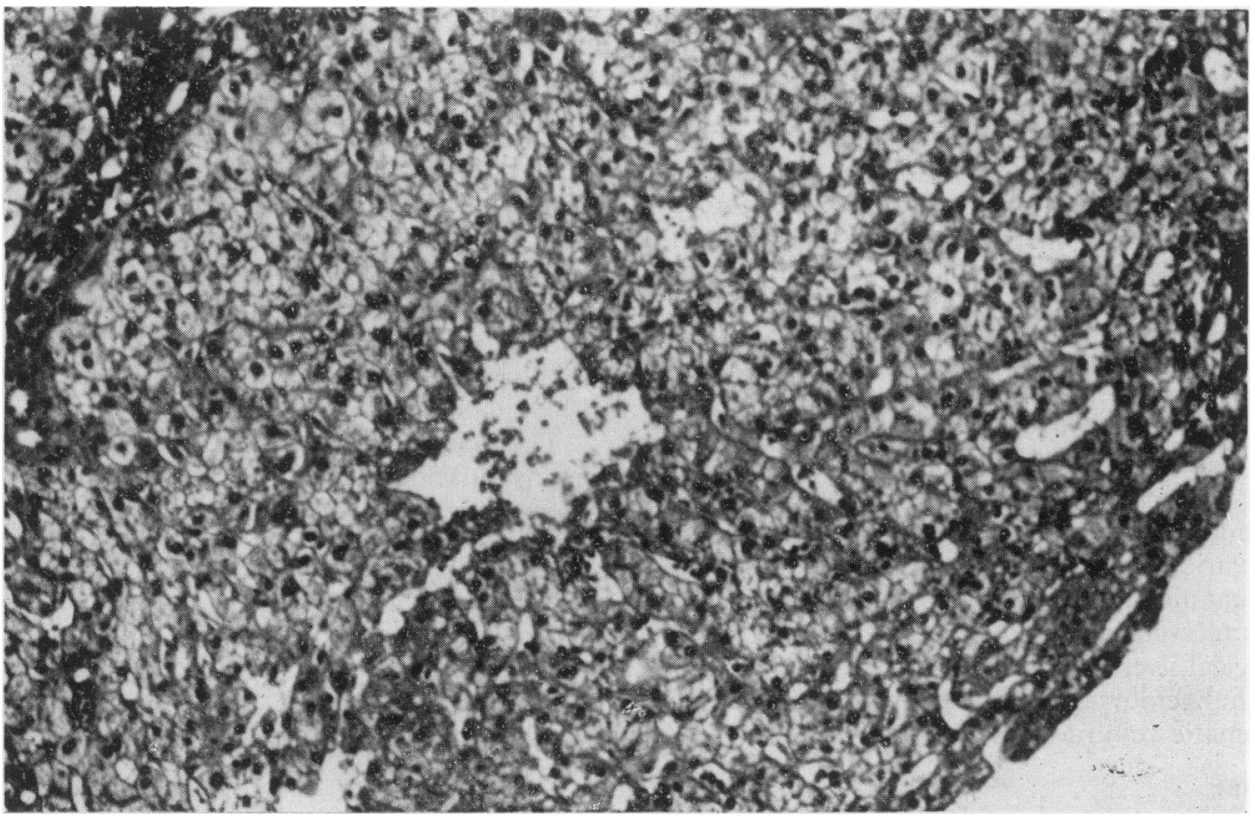

FIG. 6. Needle liver biopsy. Dilated central hepatic veins without signs of congestion. Some sinusoids show moderate dilatation. $\mathrm{HE}, \times 40$. 
enlargement of the liver, especially of the left lobe, with a characteristic excess uptake of the isotope at the centre of the liver, without filling defects (Westcott, 1973). The spleen was moderately enlarged. Because abdominal distension had caused severe discomfort to the patient, paracentesis was done four times under simultaneous plasma administration. Diuretics had been tried initially with very poor results. However the ascitic fluid was quickly reproduced. The third day after her admission, the patient had a haematemesis and melaena. The haematocrit had fallen to $30 \%$. The stools were normal 2 days later. During this time the patient had a blood transfusion. The presence of tender hepatomegaly, without significant deterioration of liver function, the early development of portal hypertension in a person who had no history or clinical signs of chronic liver disease, the rapid reproduction and the high protein content of the ascitic fluid, in connection with the finding of the liver scan led the authors from the start to a diagnosis of hepatic vein block. A liver biopsy (Fig. 2) and an inferior venacavography were performed in order to investigate the case further and to confirm the clinical diagnosis. The liver biopsy taken from a central area showed nothing characteristic apart from slight dilatation of sinusoids and a moderate fibrosis at the portal zones (Fig. 3). The inferior venacavography (Figs 2 and 3) showed a typical smooth narrowing of the hepatic segment of the hepatic vein (Westcott, 1973), this was probably due to the pressure of the hypertrophic caudate lobe. The main hepatic veins could not be visualized following Valsalva manoeuvre. An hepatic venography was arranged for the following day. Unfortunately, the patient had a severe haematemesis which was uncontrollable despite blood transfusion and the insertion of the BlakemoreSengstaken tube and she was taken to the operating theatre as an emergency.

\section{Operative findings}

During operation, the liver was found to be enlarged and congested and the spleen twice the normal size. A gross collateral circulation, including oesophageal varices, was present and the portal vein pressure was found to be $54 \mathrm{~cm}$ of water. Because of severe and continuous blood loss from the oesophageal varices, a Tanner's operation was performed. The patient died the next day. Post-mortem examination was refused.

A surgical liver biopsy showed an intense congestion with haemorragic infiltration and thrombosis of the hepatic vein radicles (Figs 4, 5 and 6).

\section{Discussion}

The clinical diagnosis of Budd-Chiari syndrome followed by confirmation of inferior venacavography and liver biopsy is well documented. The histo- logical appearance of the liver at biopsy was dif ferent from that at surgery because the materiad taken at biopsy was from an area of minimat. damage (caudate lobe) and not because of alteratior? of histology due to the progression of the disease Unfortunately, the angiographic investigation was. restricted to the inferior venacavography but according to Clain et al. (1967), Deutsch et al. (1972) and Westcott (1973), this technique alone is usualle sufficient to give the correct diagnosis. For this reason and also for the fact that it is a very simple technique, inferior venacavography has been widel $\bar{t}$ used in the investigation of occlusion of the inferioe venacava and the hepatic veins. The smoot stenosis of the venous lumen in the present case an $\Phi$. the failure of visualization of the hepatic veinsis suggest occlusion of the veins by a thrombus rather than by a neoplasm. The liver scan appearance ie also suggestive of the syndrome. The central uptaki of the liver scan is due to hypertrophy of the caudate lobe, which is not unusual in the Budd-Chiars syndrome. This can be explained by the uniquevascular supply and drainage of the caudate lobe The caudate lobe receives blood from both right an ff left hepatic arteries and from two or three separate portal veins. Of greater importance in the BuddChiari syndrome is the caudate lobe venous dran age which is by two, three or, rarely four veins iat $0^{\circ}$ the intrahepatic inferior vena cava (Westcott, 19\% Hales and Scatliff, 1966). This should make the caudate lobe much less affected than the right an left lobes, and probably accounts for the marked regenerative hypertrophy of the caudate lobe in the Budd-Chiari syndrome.

The occlusion of the hepatic veins probably begap during the sixth month of pregnancy, making this case very significant, because no trace could be found of a similar case in the literature. There have been reported only nine cases which were observed closes to time of delivery (Kahn and Spring, 1940; Deutsch et al., 1972; Chiari, 1899; Lange, 1886; Thran?. 1899; Mann and Hall, 1904; Krass, 1957; Hannock 1968).

The aetiology of the Budd-Chiari syndrome $\mathrm{re}_{0}$ mains unknown in $67 \%$ of cases. The increasing frequency of the syndrome in women taking orat contraceptives, and the increased incidence if pregnant women of venous thrombosis due tô alteration of coagulation factors (factors VII, VIII $\mathrm{X}$ and fibrinogen) (MRC Working Party Report: 1967) lead one to entertain the possibility of a cons nection between pregnancy and the Budd-Chiart syndrome in the present case.

\section{References}

ChIARI, H. (1899) Ưber die selbständinge Phlebitis oblo terans der Haupstämme der Venae hepaticae als Taderu氶 
sache. Beiträge zur pathologischen Anatomie und zur allgemeine Pathologie, 26, 12.

Clain, D., Freston, J., Kreel, L. \& Sherlock, S. (1967) Clinical diagnosis of Budd-Chiari syndrome. American Journal of Medicine, 43, 544.

Deutsch, V., Rosenthal, T., Adar, R. \& Moses, M. (1972) Budd-Chiari syndrome. Study of angiographic findings and remarks on etiology. American Journal of Roentgenology, Radium Therapy and Nuclear Medicine, 116, 430.

Hales, M.R. \& SCatliff, J.H. (1966) Thrombosis of the inferior vena cava and hepatic viens (Budd-Chiari syndrome). Annals of Internal Medicine, 64, 768.

Hannock, K.W. (1968) The Budd-Chiari syndrome in pregnancy. Journal Obstetrics and Gynaecology of the British Commonwealth, 75, 746.

KAHN, S. \& SPRING, M. (1940) Thrombosis of hepatic veinsChiari syndrome: Report of case with biopsy and venous pressure determination. Annals of Internal Medicine, 14, 1075.
KRASS, I.M. (1957) Chiari syndrome: Report of case following pregnancy. Journal Obstetrics and Gynaecology of the British Commonwealth, 64, 715.

LANGE, W. (1886) Ein Fall von Lebervenenobliteration. Inaugural Dissertation, University of Kiel, p. 18, Schmidt \& Klauning, Kiel.

MANN, J.D. \& HALL, J.W. (1904) Obstruction of the inferior vena cava. Edinburgh Medical Journal, 16, 56.

MRC WORKING PARTY RePORT (1967) Risk of thromboembolic disease in women taking oral contraceptives. British Medical Journal, 2, 355.

PARKer, R.G.F. (1959) Occlusion of the hepatic veins in man. Medicine, 38, 369.

ThraN, J.H. (1889) Uber einen Fall von Lebervenenobliteration. Inaugural Dissertation, University of Kiel, Schmidt \& Klauning, Kiel. (Cited by Hannock, K.W., 1968).

Westcott, J.L. (1973) The Budd-Chiari syndrome. Case report with angiographic findings. American Journal of Gastrenterology, 60, 625 . 